\title{
LINEAR Breakthrough Project: Large-Scale Implementation of Smart Grid Technologies in Distribution Grids
}

\author{
B. Dupont, Student Member, IEEE, P. Vingerhoets, P. Tant, K. Vanthournout, W. Cardinaels, \\ T. De Rybel, E. Peeters, R. Belmans, Fellow, IEEE
}

\begin{abstract}
The LINEAR project (Local Intelligent Networks and Energy Active Regions) focuses on the introduction and implementation of innovative smart-grid technologies in the Flanders region, and aims at a breakthrough in the further development and deployment of these solutions. It consists of a research component and a large-scale residential pilot, both focusing on active demand-side management of domestic loads. This paper describes the unique approach, the main objectives and the current status of this project. Selected business cases and target applications are discussed in detail.
\end{abstract}

Index Terms - smart grid, demand side management, demand response

\section{INTRODUCTION}

LINEAR is a large-scale research and demonstration project focused on the introduction of smart grids, and more specifically on active demand strategies, at residential premises in the Flanders region in Belgium. This region is of special interest due to its high standard of living and high population density. Since the region has few economically exploitable natural resources, energy prices are high. These conditions, combined with the European 20-20-20 goals and the Strategic Energy Technology (SET) plan put forward by the European Commission [1], fostered a strong incentive with the local government, industry, and domestic users to investigate new technologies. It is expected that in a few years time, the increasing integration of distributed energy resources (DER) will severely impact the operation of the distribution grid, unless active demand strategies are implemented by then. Therefore, the Flanders region, which can be thought of as one large city, is an ideal test-bed to implement a smart-grid trial. The LINEAR project aims at a technological as well as an implementation breakthrough of active demand techniques. Its focus is twofold. On the one hand, the project deals with

The work is supported by the Ministry of Science (Minister I. Lieten) via the LINEAR project organized by the agency for Innovation through Science and Technology (IWT).

B. Dupont, P. Vingerhoets, P. Tant, T. De Rybel and R. Belmans are with the Department of Electrical Engineering (ESAT), Research Group Electrical Energy and Computer Architectures (ELECTA), KU Leuven, Kasteelpark Arenberg 10,3001 Leuven, Belgium (benjamin.dupont@esat.kuleuven.be). K. Vanthournout, W. Cardinaels and E. Peeters are with the Flemish Institute for Technological Research (VITO), Boeretang 200, B-2400 Mol, Belgium. Both organizations are cooperating in EnergyVille, Dennenstraat 7, 3600 Genk, Belgium. research and development efforts required to deploy active demand technologies. On the other hand, it also aims at implementing these technologies in a field test, by setting up a residential pilot.

The project started in May 2009 and receives a partial funding from the Flemish government for the academia and research institutes (ESAT/ELECTA-KU Leuven, VITO, IBBT and IMEC). Furthermore, several industrial partners, including Belgacom, Eandis, EDF-Luminus, Fifthplay, Infrax, Laborelec, Miele, Siemens, Telenet and Viessman, invest and actively participate in the project and also review the work plan, activities and output for relevance and quality. Finally, the Flemish regulator for the electricity and gas market (VREG), as well as industry and government interest groups (Agoria, EWI, VOKA) either partake in, or provide their input to, the steering board. Especially the multidisciplinary collaboration and input of all parties, academia, research institutes, government, industrial partners coming from the telecom, energy, household devices and ICT sector, make this project very challenging, but promising. Compared with other European initiatives, such as ADDRESS [2] and EU-DEEP [3], LINEAR is unique in a number of ways:

1) The main focus is on the implementation of automated active demand technologies in the distribution grid, and a field trial with around 250 end users involved.

2) The project combines a customer centered approach with a focus on technological research, where every aspect is well supported by an extensive economical framework. The knowledge exchange and cooperation between these three viewpoints provides the necessary means to come to a successful implementation of active demand in a real field trial.

3) The collaboration with and cooperation of relevant stakeholders allows the clustering of necessary competences and experience in the field of smart grids. Since the distribution system operators (DSOs) are also involved, the link with their smart metering pilots provides a detailed insight in user profiles of over 1000 end users.

This paper provides an overview of the approach, main objectives and current status of the LINEAR project. First, the general project structure and high-level goals are briefly explained in Section 2, followed by a detailed discussion of 
the targeted business cases and their economical feasibility in Section 3. Section 4 describes the practical implementation of the residential field test, including an overview of the control strategies deployed in this context. The subsequent section highlights some of the recent research achievements of the project. Finally, conclusions are given in Section 6.

\section{PROJECT STRUCTURE AND HIGH-LEVEL GOALS}

One of the high-level goals of LINEAR is to define the development needs to enable the introduction of active demand techniques, and subsequently to initiate this technology innovation in additional projects. Furthermore, it is the intention to create an implementation breakthrough of active demand by means of a field trial, and to build up a unique research infrastructure in Flanders, based on a residential test site and a laboratory infrastructure to back up the field tests.

The methodology used in LINEAR is shown in Fig 1. Basically, there are two main components: one focusing on research and development — which aims at technological breakthroughs — and one primarily focusing on an implementation breakthrough by setting-up a residential pilot.

The research part has to lead to the definition of concrete technological concepts for smart energy supply. As Fig. 1 shows, this is done in several work packages, each focusing on a specific aspect. First, user and device profiles are gathered by a full-scale monitoring and sub-metering campaign. These profiles are linked to different types of users, based on results of enquiries with end users to study user acceptance for active demand and smart grids. Second, profiles of devices are linked to the energy use of the building and the flexibility of the different users and devices is studied. Another research topic is the combination of distributed generation units, such as photovoltaic systems, and storage, taking into account thermal as well as electrical storage. Furthermore, the impact of increasing DER on related networks (electricity, communication, gas) is studied, including the possibility of grid reconfiguration in Flanders. And finally, the application of plug in hybrid electric vehicles as either a load, a storage means or a producer is also studied in detail.

The knowledge about these different aspects is combined in order to define optimal combinations and control strategies of loads, storage and production units and to integrate these in an estimation of the potential for the measuring sites and to formulate general advices for other projects. This process is based on the development of algorithms and simulation tools to support the field test.

To stimulate the implementation breakthrough, a demonstration of the smart grids concept in an existing typical Flemish residential area is foreseen. This pilot-site will be fully operational in 2013. Active demand management of around 250 buildings will be realized within the project, including non-predictable energy resources. Both the research and implementation part of the project are constantly in close cooperation with the Energy Markets work package. This work package assesses market aspects such as current and future market structures, regulation and business cases for active demand. The four most viable business cases are selected and evaluated in the LINEAR field test. This is explained in greater detail in the next sections.

\section{BUSINESS CASES AND ECONOMICAL FEASIBILITY}

The current market structure faces several challenges, which will only become more stringent in the near future. Residential electric energy consumption continuously increases due to electrification by the introduction of heat pumps and plug-in hybrid electric vehicles (PHEVs). The rise of distributed generation and renewable energy production leads to a generation paradigm shift [4]. Finally, the ageing of power systems induces a replacement wave of electrical infrastructure in the coming decades [5], [6]. Regardless of these challenges, the power system needs to operate in an economic and reliable way. Active Demand (AD) for residential consumers is a means to accomplish this, as a

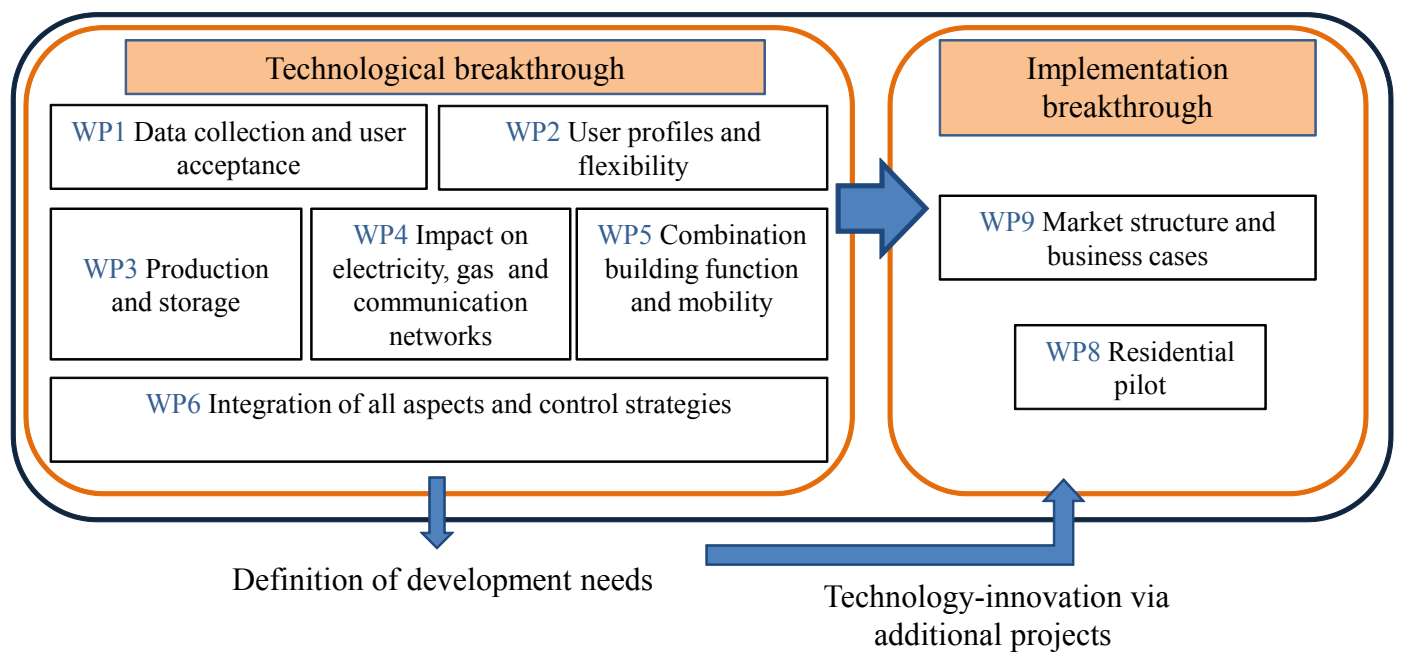

Fig. 1. General overview of the project structure, and the two main components aiming at a technological as well as an implementation breakthrough. 
significant amount of flexible resources is available on the demand side [7]. Although $\mathrm{AD}$ offers a solution for the upcoming challenges, it impacts the roles and responsibilities of the current market actors. Moreover, new actors, like an aggregator aiming at optimizing energy supply and consumption, can arise [8]. To seize this changing market structure, the LINEAR project explores four Business Cases (BCs) based on demand response programs (Fig. 2): portfolio management, wind balancing, load pattern control of low voltage distribution transformers, and voltage control in low voltage lines:

\section{A. Portfolio management}

The portfolio management $\mathrm{BC}$ is induced by the generator and the retailer. Generators offer their electricity output in a wholesale market, in which retailers buy electricity. This results in wholesale prices which typically fluctuate during the year and even within a day. Peak periods are characterized by higher generation costs, because expensive peaking plants are ramped up to cover demand. During off-peak periods, demand is usually covered by cheaper base load plants, facing mustrun requirements. Although wholesale prices vary, residential tariffs are typically kept constant for months, reflecting average costs during that period. Therefore, residential consumers get no economic incentive to shift consumption away from peak periods. The incapability for residential consumers to react, results from the lack of metering and realtime billing [9]. Moreover, policy makers believed that the responsiveness of electricity consumers to dynamic tariffs was too low in comparison with the implementation costs [10].

If more renewable electricity generation from wind and solar energy is integrated, the inconsistency is only strengthened, as the impact of predicted wind power penetration on wholesale prices is considerable [11], [12].

The European Commission's strategy for competitive, sustainable and secure energy towards 2020 tackles these shortcomings and creates a framework for smart metering and $\mathrm{AD}$ [13]. This makes the consumer capable of participating in the electricity market by shifting consumption to lower price periods.

In the portfolio management $\mathrm{BC}$, residential consumers help operating the power system in a more efficient way by responding to dynamic electricity prices. This leads to several short-term and long-term benefits. In the short term, energy cost are reduced by prioritizing cheaper renewable electricity generation and avoiding the ramping up of more expensive peaking plants [14]. In the long term, utilities avoid capacity, transmission and distribution costs [15], because the system can be tuned on a lower peak demand due to sustained demand response. Moreover, the large scale integration of renewable energy in the long term is facilitated by $\mathrm{AD}$, leading to environmental benefits [16].

As Fig. 2 shows, the $\mathrm{BC}$ calculation elaborates these benefits in two parts. First, the business model is developed, modeling all market actors influenced by the business case together with the interactions between them. Second, the economic feasibility of the business model is assessed based

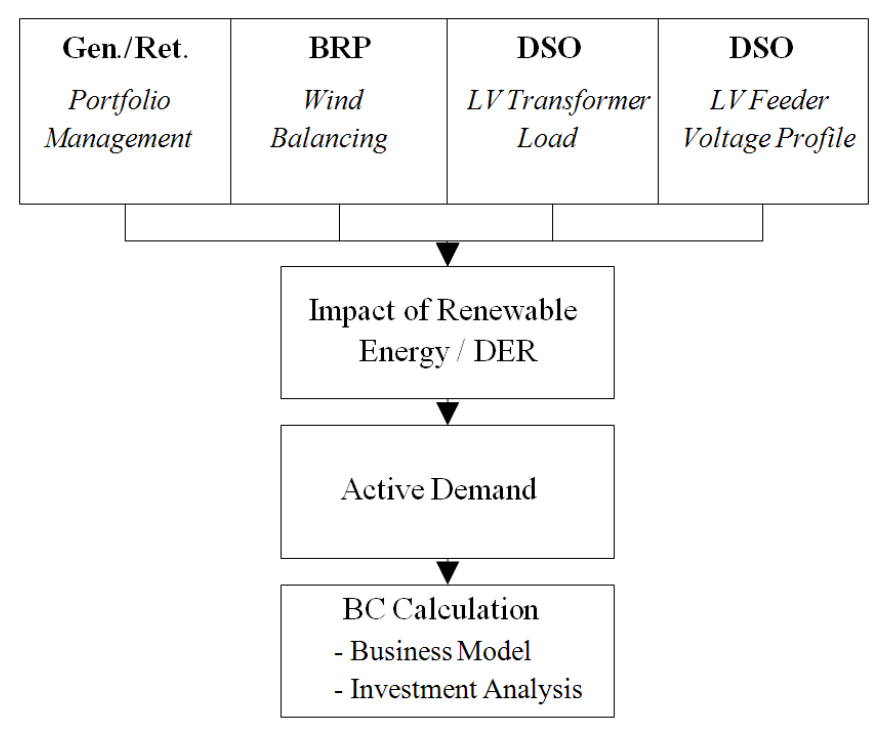

Fig. 2. Business cases induced by market actors.

on an investment analysis. Although the costs and benefits defer depending on the business case, the same methodology is used throughout each business case.

\section{B. Wind balancing}

The wind balancing $\mathrm{BC}$ is induced by the Balancing Responsible Party (BRP) in charge of controlling the balance of injection and off-take in its perimeter on a quarter-hourly basis. If a BRP is not able to control the balance due to unexpected events, the instantaneous imbalance is managed by the Transmission System Operator (TSO). In return, the TSO transfers the costs involved for making use of power reserves to the BRP. This is stated as the imbalance costs.

Renewable energy sources are characterized by their high variability, low predictability and low controllability. This implies that the imbalance risk of a BRP with renewable energy sources in its portfolio is higher. A BRP can counter this risk by increasing the predictability and controllability of its portfolio. One way to accomplish this is by making use of $\mathrm{AD}$. In the wind balancing $\mathrm{BC}$, a BRP faces real-time imbalances in his portfolio caused by deviations from the wind power prediction. The imbalance can be minimized by controlling real-time flexible loads at residential premises in its control area.

\section{Low-voltage distribution transformer load}

The $\mathrm{BC}$ which controls the load pattern of low-voltage distribution transformers is induced by the DSO, who is responsible for a reliable operation of the distribution grid and a reliable supply of electrical energy to end users. Within this business case, the DSO is the actor who manages the load on the low voltage transformer. Although low-voltage transformers are designed to continuously operate at nominal power, the load profile of the transformer typically varies in a cyclic way, with different consumption peaks during the day. With a cyclic load, the ageing of the transformer accelerates during the peak period due to higher temperatures in the transformer. As described in [17] and [18], the relation 
between temperature and life time is non-linear. This implies that the ageing is higher when the temperature varies more, given that the average temperature is the same.

The introduction of distributed renewable energy sources and DER, including PHEVs, influences the altitude and variability of the load profile at the transformer. Photovoltaic generation in the distribution network reduces the total load delivery, although the peak loads remain almost unchanged. PHEVs add peak loads, contributing to the ageing of the transformer [19]. One way to cope with this problem is by making use of AD. In this business case, the DSO decreases the peak load of a given distribution transformer by controlling flexible energy resources at residential premises in its network in real-time, to defer or decrease network investments.

\section{Voltage profile}

The $\mathrm{BC}$ which controls the voltage level in low-voltage feeders is also induced by the DSO. Traditionally, voltage levels are set at the beginning of the feeder, using tap changing transformers. However, line voltages tend to decrease when the feeder is heavily loaded, or increase due to the impact of distributed generation units. Standards limit the lower and upper boundaries of the voltage level [20].

The introduction of distributed renewable energy sources and DER add complexity to this reasoning. Due to the boom of photovoltaic panels, voltage rises can occur going above the upper boundary. On the other hand, the integration of PHEV leads to excessive voltage drops unless the charging is coordinated. One way to cope with these fluctuations is AD.

In this business case, a DSO optimizes the voltage profile on a LV feeder by controlling real-time flexible energy resources at residential premises in its grid network to defer or decrease network investments.

\section{LARGE-SCALE RESIDENTIAL PILOT PROJECT}

The LINEAR project includes a large-scale field trial in which residential active demand technology is validated in real- life conditions. Next to technical validation, this includes evaluating the social acceptance of the various scenarios that are executed. Therefore, a large-scale enquiry was conducted, involving a total of almost 2000 users. The results of this social investigation were linked to the consumption profiles of the customers. Customer sampling techniques were used to guarantee the representativeness of the consumption profiles [21]. This yielded a set of representative electricity and gas demand profiles, which is used in the simulations of the LINEAR project (see section $\mathrm{V}$ ). At the end of the field trial an enquiry towards user acceptance is planned with all participants.

The field trial consists of three phases, i.e., a first phase consisting of 33 so-called friendly users - colleagues and family of LINEAR co-workers - where technology is validated after the lab test phase and before it is rolled out full scale in the other phases. Phase 1 started beginning 2011 and remains active during the full length of the LINEAR project. The second phase targets at 100 users, geographically dispersed over the Flanders region and focuses on the retailer/BRP business cases. The third phase is geographically concentrated in two city regions, where the LINEAR field trial will install active demand equipment in an additional 100 houses and make use of the DSO's local smart metering infrastructure. This implies that phase 3 will enable LINEAR to measure and react in real-time to stimuli from the local distribution grid. Phase 2 is active from April 2013 till April 2014, phase 3 from July 2013 till July 2014, each preceded by a year of reference measurements at the participant's premises.

Fig. 3 gives a general overview of the active demand infrastructure that is deployed for the phase 1 users in the field test. On top of the system resides the LINEAR Smart Grid server, which is a combination of standard application software and an in-house developed data analysis tool [22].

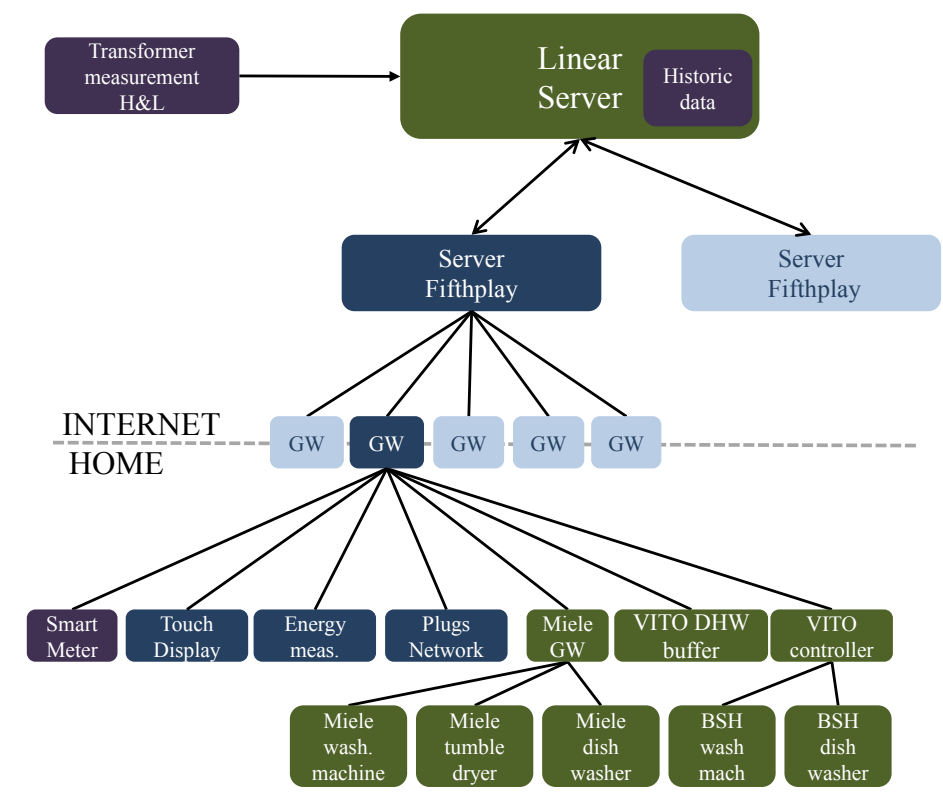

Fig. 3. The LINEAR field trial ICT infrastructure. 
The LINEAR server is communicating with the servers of the industrial partners that take the role of gateway (GW) provider. Each GW provider maintains a platform consisting of a server which accepts the active demand control primitives, and gateways installed at the participant's premises which control the local smart devices and the user interfaces. The control systems and algorithms that convert high-level active demand commands into smart device actions are integrated into the GW provider platforms.

Next to a gateway, the ICT infrastructure installed at the residential premises consists of a touch display to communicate pricing and other information to the participants, an energy meter at the mains connection to measure the total energy consumption and production in the household, and smart plugs, which are mainly used as a sub-metering system. The smart appliances currently scheduled for deployment in the LINEAR project are:

1) Miele Smart Grid Ready washing machines, tumble dryers and dishwashers, using power line communication (PLC) to communicate with a dedicated Miele gateway, which in turn is controlled via an XML interface over Ethernet by the main GW.

2) Converted electric domestic hot water (DHW) buffers using a custom-developed smart DHW controller. An in-house prototype was developed and demonstrated in a lab setup [23]. The controller communicates to the gateways by means of open LINEAR JSON interfaces over Ethernet, Wi-Fi or PLC. The communication medium is decided upon per residence in function of the local structural limitations.

3) Regular 'non-smart' washing machines, tumble dryers and dishwashers, which are enhanced with a remote delayed start, using the custom-developed VITO smart grid controller box.

4) Finally, also smart heat pump systems are investigated on their feasibility within the LINEAR time frame.

It should be noted that the smart devices are designed and controlled in such a way that the impact on the comfort level of the participant is minimized. All devices have comfort settings which always take precedence over the active demand control commands.

As discussed in the previous section, a wide selection of potential applications of residential flexibility or business cases are investigated. Portfolio management tries to achieve a better production/consumption balance, based on day-ahead predictions and prices and focusing on renewables, such as wind and sun. Real-time intra-day balancing of wind production uses residential active demand to cover the delta between predicted and actual wind production. Furthermore, the load pattern on low-voltage transformers and voltage deviations in distribution grids are also considered. In order to achieve these technical goals, different control primitives are evaluated. Fig. 4 gives an overview of which control strategies are used for what business cases and in which field trial phase the combinations are validated. The number on the graph indicates the phase of the field trial. On the left axis, for every business case the different control strategies are indicated:

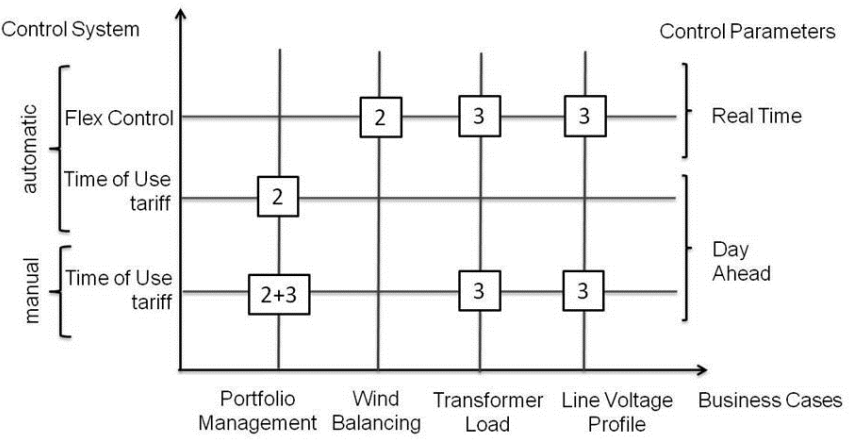

Fig. 4. Business cases versus control strategies during the LINEAR field trial.

1) Manual Time of Use (ToU): variable prices for fixed timeslots are communicated day-ahead to the participants using web services and touch displays, such that the participants can shift their electricity consumption accordingly. The participants receive a financial remuneration as an incentive, based on their shifting and compared to reference consumption profiles compiled during the reference measurements.

2) Automated ToU: identical to manual ToU, safe that smart devices automatically optimize their energy consumption in function of the ToU tariffs.

3) Automatic flexibility control: multiple houses are combined into a cluster, with the total net consumption or production of the houses combined as the prime control parameter. Active demand commands essentially increase or decrease this value and are executed by controlling the smart devices in the cluster.

At the time of publication, the roll out for the phase 2 participants is complete, and reference measurements are ongoing. Meanwhile the selection of the phase 3 participants is being conducted in the region of Hombeek-Leest. On the technical side, algorithms are being developed and implemented to evaluate each of the business cases and define the interaction between the LINEAR server and the gateways.

\section{SCIENTIFIC RESEARCH AND SIMULATION TOOLS}

As discussed previously, the majority of the research in the project serves as input for the different phases of the field test, which in turn provides data to validate the theoretical approach. The main research components of the LINEAR project are the impact of DER on electricity and gas networks, the integration of electric vehicles and electrical and thermal storage.

One of the key issues in the upcoming decade is dealing with an increasing penetration of photovoltaic (PV) installations in the distribution grid. This can lead to unpredictable production peaks, which can cause power quality problems in the distribution grid. To investigate the scale and magnitude of these problems, load flow simulations have been performed on four typical Flemish feeders, from a rural to a city environment [24]. Important input of the simulations is the detailed structure of the feeders and the load profiles, which were provided by the industrial partners and 
analyzed within the LINEAR project [21].

Not only the integration of PV installations presents challenges for the distribution grid nowadays, also the rising amount of electric vehicles can significantly increase the peak load. First, an availability analysis of the Flemish fleet was performed, together with the specific energy consumption for realistic driving behavior [25]. Based on these models, the energy consumption and charging needs of electric vehicles is determined. With this information, the impact of electric vehicles on the peak load can be estimated, while charging coordination mechanisms can be developed to spread the peak load over time. Different coordination strategies of electric vehicles are discussed in a literature study [26]. Coordinated charging of electric vehicles was shown to have a positive impact on the peak power demand [27]-[29], while a droop control can effectively prevent power quality problems in the distribution grid [30]. In addition to these coordination mechanisms, the scheduling of a fleet electric vehicles is modeled as a stochastic optimization problem in [31]. A selflearning algorithm for performing demand side management on a more general cluster of devices was developed in [32].

One of the solutions to power quality issues in the distribution grid, caused by distributed renewable energy production or electric vehicles, is electrical or thermal storage of the produced energy. To probe the economic viability of electrical storage, an economic model of battery energy storage systems (BESS) was developed [33]. The impact of these battery storage systems on the electrical residential distribution grid was studied in [34], where a trade off between voltage regulation, power reduction and annual cost was proposed. The effectiveness of BESS to mitigate voltage violations was studied in [35]. Considering thermal energy storage, the flexibility potential of residential heat pumps combined with a storage tank is assessed in [36]. The flexibility of combined heat and power (CHP) systems in combination with thermal energy storage was discussed in [37], [38]. The impact of a large-scale introduction of CHP on the gas network was investigated in [39], where the importance of a thermal storage tank was stressed to limit the impact on the gas demand.

Also on the economic part of the LINEAR project, research has been performed to work out the new market models, identify possible new actors and evaluate the business cases of the LINEAR project.

For the portfolio management business case, the customer receives dynamic energy prices providing an incentive to modify its consumption profile. The short term advantages of this system were investigated in [40]. In [41], a methodology is described which allows to determine the flexibility of a set of household appliances and the economic value of offering this flexibility. An automatic scheduling method to shift the electricity consumption of white good appliances to the cheapest time is developed in [42]. More variable dynamic tariff structures were exploited as well, which will be tested extensively in the field trial.

For the wind balancing case, active demand can play an important role in reducing the imbalance costs that balancing responsible parties have to pay. The share of shifting flexible demand in reducing imbalance volume, compared with other balancing actions like thermal generator dispatch or intra-day market trading, was shown to be significant in [43].

The effect of peak shaving on the life time of transformers is assessed in [44]. Results show that active demand reduces the aging of transformers significantly when they are loaded close to the rated load.

\section{CONCLUSIONS}

The increasing integration of DER and higher penetration levels of PHEVs expected in the near future, severely impact the operation of the distribution grid and challenge the existing electric and gas network infrastructure. Active demand concepts, which take advantage of the flexibility and resources of residential consumers, are generally adopted as a potential solution for these issues. However, before applying such methods on a larger scale, extensive research and development efforts are still required to further refine active demand technologies and control strategies. Also, on a more fundamental level, the market structure and the role of current market players should be reconsidered in view of active demand. The LINEAR project addresses these aspects and aims at a breakthrough at the technological level, by developing hardware solutions and control algorithms in close collaboration with international industrial partners, and at the economic level, by investigating which business cases are feasible and meet the requirements of the consumer, the DSO, and other market actors. At the technological side, main research results are achieved on the domains of electric and thermal storage, impact of DER on electricity/gas networks and integration of electric vehicles in the LV distribution grid. The different business cases of the LINEAR project are evaluated in an economic framework, and new market structures are being developed. Both technological and business strategies are implemented in a large-scale field trial, involving around 250 residential consumers in the Flanders region.

\section{REFERENCES}

[1] European Union, "The European Strategic Energy Technology Plan Towards a Low-carbon Future", 2010, 16 pages.

[2] ADDRESS (Active Distribution network with full integration of Demand and distributed energy RESourceS), 2011. [Online]. Available: http://www.addressfp7.org

[3] EU-DEEP (European Distributed EnErgy Partnership), 2011. [Online]. Available: http://www.eudeep.com

[4] A.-M. Brobely, and J. F. Kreider, Distributed Generation: The Power Paradigm for the New Millennium, $1^{\text {st }}$ ed., Boca Raton, FL: CRC Press, June 2001.

[5] R.E. Brown, and H.L. Willis, "The Economics of Aging Infrastructure," Power and Energy Magazine, Vol. 4, pp. 36-43, May 2006.

[6] Z. Li, and J. Guo, "Wisdom about age," Power and Energy Magazine, Vol. 4, Pp. 44-51, May 2006.

[7] A. Faruqui, and S. George, "The Value of Dynamic Pricing in Mass Markets," The Electricity Journal, Vol. 36, Issue 6, Pp. 45-55, July 2002.

[8] J. Deuse, D. Benintendi, P. J. Agrell, and P. Bogetoft, "Power System and Market Integration of DER, The EU-DEEP Approach," $18^{\text {th }}$ Int Conf. on Electricity Distribution, CIRED, Italy, June 2005.

[9] S. Stoft, Power System Economics: Designing Markets for Electricity, New York: Wiley-IEEE Press, 2002, p.15. 
[10] J. Torriti, M. G. Hassan, and M. Leach, "Demand Response Experience in Europe: Policies, Programs, and Implementation," Energy, Vol. 35, Issue 4, Pp. 1575-1583, April 2010.

[11] T. Jónsson, P. Pinson, and H. Madson, "On the Market Impact of Wind Energy Forecasts," Energy Economics, Vol.32, Issue 2, Pp. 313-320, March 2010.

[12] F. Sensfu $\beta$, M. Ragwitz, and M. Genoese, "The merit-order effect: A detailed analysis of the price effect of renewable electricity generation on spot market prices in Germany," Energy Policy, Vol.36, Issue 8, Pp. 3086-3094, August 2008.

[13] European Commission, "Energy 2020: A Strategy for Competitive, Sustainable and Secure Energy," SEC(2010) 1346, Brussels, 2010.

[14] C. De Jonghe, E. Delarue, R. Belmans, and W. D'haeseleer, "Integrating Real-time Pricing into Unit Commitment Programming," $17^{\text {th }}$ Power Systems Computation Conference (PSCC), Stockholm, Sweden, 2011.

[15] G. Strbac, "Demand Side Management: Benefits and Challenges", Energy Policy, Vol.36, Issue 12, Pp. 4419-4426, Dec. 2008.

[16] C. De Jonghe, B.F. Hobbs, and R. Belmans, "Integrating Short-term Demand Response into Long-term Investment Planning," EPRG working paper 1113, Cambridge Working Paper in Economics 1132, University of Cambridge, 2011.

[17] IEEE Guide for Loading Mineral-Oil-Immersed Overhead and PadMounted Distribution Transformers rated $500 \mathrm{kVA}$ and less with $65^{\circ} \mathrm{C}$ or $55^{\circ} \mathrm{C}$ average winding rise, Standard C57.91-1981, 1981.

[18] IEEE Guide for Loading Mineral-Oil-Immersed Transformers, Standard C57.91-1995, 1996.

[19] S. Blumsack, C. Samaras, and P. Hines, "Long-Term Electric System Investments to Support Plug-in Hybrid Electric Vehicles," 2008 IEEE Power and Energy Society General Meeting - Conversion and Delivery of Electrical Energy in the 21st Century, Pp. 1-6, Pittsburgh, July 2008.

[20] Voltage Characteristics of Electricity Supplied by Public Distribution Systems, Standard EN 50160, July 2004.

[21] W. Labeeuw, and G. Deconinck, "Customer Sampling in a Smart Grid Pilot," 2012 IEEE PES General Meeting, San Diego, CA, USA, July 2012.

[22] W. Labeeuw, S. Claessens, K. Mets, C. Develder, and G. Deconinck, "Infrastructure for Collaborating Data-Researchers in a Smart Grid Pilot," IEEE PES Int. Conference and Exhibition on Innovative Smart Grid Technologies (ISGT Europe), Berlin, Germany, October 14-17, 2012, submitted for publication.

[23] K. Vanthournout, R. D'hulst, D. Geysen, and G. Jacobs, "A Smart Domestic Hot Water Buffer," IEEE Transactions on Smart Grid, Issue 99, Pp 1-7, 2012.

[24] C. Gonzalez, J. Geuns, S. Weckx, T. Wijnhoven, P. Vingerhoets, and T. De Rybel, "LV Distribution Network Feeders in Belgium and Power Quality Issues due to Increasing PV Penetration Levels," 2012 IEEE PES Int. Conference and Exhibition on Innovative Smart Grid Technologies (ISGT Europe), Berlin, Germany, October 14-17, 2012, submitted for publication.

[25] J. Van Roy, N. Leemput, S. De Breucker, F. Geth, P. Tant, and J. Driesen, "An Availability Analysis and Energy Consumption Model for a Flemish Fleet of Electric Vehicles," European Electric Vehicle Congress (EEVC), Brussels, Belgium, October 26-28, 2011.

[26] N. Leemput, J. Van Roy, F. Geth, P. Tant, B. Claessens, and J. Driesen, "Comparative Analysis of Coordination Strategies for Electric Vehicles," 2011 IEEE PES Int. Conference and Exhibition on Innovative Smart Grid Technologies (ISGT Europe), December 5-7, 2011, Manchester, United Kingdom.

[27] N. Leemput, F. Geth, B. Claessens, J. Van Roy, R. Ponnette, and J. Driesen, "A Case Study of Coordinated Electric Vehicle Charging for Peak Shaving on a Low Voltage Grid," 2012 IEEE PES Int. Conference and Exhibition on Innovative Smart Grid Technologies (ISGT Europe), Berlin, Germany, October 14-17, 2012, submitted for publication.

[28] K. Mets, T. Verschueren, F. De Turck, and C. Develder, "Evaluation of Multiple Design Options for Smart Charging Algorithms," 2nd IEEE Int. Conf. on Communications Workshops (ICC), Kyoto, Japan, 2011.

[29] K. Mets, T. Verschueren, F. De Turck, and C. Develder, "Exploiting V2G to Optimize Residential Energy Consumption with Electrical Vehicle (Dis)charging," $1^{\text {st }}$ IEEE Int. Workshop Smart Grid Modeling and Simulation (SGMS 2011) at IEEE SmartGridComm 2011, Brussels, Belgium, Oct. 2011.

[30] F. Geth, N. Leemput, J. Van Roy, J. Büscher, R. Ponnette, and J. Driesen, "Voltage Droop Charging of Electric Vehicles in a Residential Distribution Feeder," 2012 IEEE PES Int. Conference and Exhibition on Innovative Smart Grid Technologies (ISGT Europe), Berlin, Germany, October 14-17, 2012, submitted for publication.

[31] F. Ruelens, S. Vandael, W. Leterme, B.J. Claessens, M. Hommelberg, T. Holvoet, and R. Belmans, "Demand Side Management of Electric Vehicles With Uncertainty on Arrival and Departure Times," 2012 IEEE PES Int. Conference and Exhibition on Innovative Smart Grid Technologies (ISGT Europe), Berlin, Germany, October 14-17, 2012, submitted for publication.

[32] B. J. Claessens, S. Vandael, F. Ruelens, and M. Hommelberg, "Selflearning Demand Side Management for a Heterogeneous Cluster of Devices with Binary Control Actions," 2012 IEEE PES Int. Conference and Exhibition on Innovative Smart Grid Technologies (ISGT Europe), Berlin, Germany, October 14-17, 2012, submitted for publication.

[33] F. Geth, J. Tant, T. De Rybel, P. Tant, D. Six, and J. Driesen, "Technoeconomical and Life Expectancy Modeling of Battery Energy Storage Systems," 21st Int. Conf. on Electricity Distribution (CIRED), Frankfurt, 6-9 June 2011.

[34] J. Tant, F. Geth, D. Six, P. Tant, and J. Driesen, "Multi-Objective Battery Storage to Improve PV Integration in Residential Distribution Grids," IEEE Transactions on Sustainable Energy, accepted for publication.

[35] T. Verschueren, K. Mets, M. Strobbe, C. Develder, B. Meersman, and L. Vandevelde, "Assessment and Mitigation of Voltage Violations by Solar Panels in a Residential Distribution Grid," $2^{\text {nd }}$ IEEE Int. Conf. on Smart Grid Communications (SmartGrid Comm), Pp 540-545, Brussels, Belgium, Oct. 2011.

[36] D. Six, J. Desmedt, D. Vanhoudt, and J. Van Bael, "Exploring the Flexibility Potential of Residential Heat Pumps Combined with Thermal Energy Storage for Smart Grids," 21st Int. Conf. on Electricity Distribution (CIRED), Frankfurt, Germany, 6-9 June 2011.

[37] T. Nuytten, and D. Six, "Flexibility of a Combined Heat and Power System Coupled to Thermal Energy Storage," presented on the Conf. on Innovation for Sustainable Production (i-SUP), Bruges, Belgium, May 6-9, 2012.

[38] T. Nuytten, and D. Six, "Assessment of the Flexibility of a Combined Heat and Power System with Thermal Energy Storage at Residential Level," 12th Int. Conf. on Energy Storage (Innostock), Lleida, Spain, May 16-18, 2012.

[39] J. Vandewalle, N. Keyaerts, and W. D'haeseleer, "The Role of Thermal Storage and Natural Gas in a Smart Energy System," $9^{\text {th }}$ IEEE Int. Conf. on the European Energy Market (EEM), Florence, Italy, May 2012.

[40] B. Dupont, C. De Jonghe, K. Kessels, and R. Belmans, " Short-term Consumer Benefits of Dynamic Pricing," $8^{\text {th }}$ IEEE, Int. Conf. on the European Energy Market (EEM), Zagreb, Croatia, May 2011.

[41] R. D'hulst, K. Kessels, and B. Dupont, "Residential Demand Response: Flexibility Assessment with Dynamic Prices," IEEE Transactions on Smart Grid, submitted for publication.

[42] B. Dupont, J. Tant, and R. Belmans, "Automated Residential Demand Response Based on Dynamic Pricing," 2012 IEEE PES Int. Conference and Exhibition on Innovative Smart Grid Technologies (ISGT Europe), Berlin, Germany, October 14-17, 2012, submitted for publication.

[43] M. T. Mekonnen, B. Dupont, K. de Vos, K. Kessels, and R. Belmans, "Optimizing the Use of Flexible Residential Demand for Balancing Wind Power," 2012 IEEE PES Int. Conference and Exhibition on Innovative Smart Grid Technologies (ISGT Europe), Berlin, Germany, October 14-17, 2012, submitted for publication.

[44] J. Jargstorf, K. Vanthournout, T. De Rybel, and D. Van Hertem, "Effect of Active Demand on Transformer Lifetime Expectation," 2012 IEEE PES Int. Conference and Exhibition on Innovative Smart Grid Technologies (ISGT Europe), Berlin, Germany, October 14-17, 2012, submitted for publication. 


\section{BIOGRAPHIES}

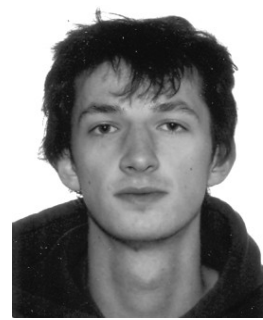

Benjamin Dupont (S'10) was born in Belgium on September 2, 1986. He received his master degree in commercial engineering in 2009 at the Faculty of Business and Economics of the KU Leuven, Belgium. Since 2009, he is working as a Research Assistant towards a Ph.D. in the research group ELECTA, department of Electrical Engineering of the KU Leuven. His research interests include the implementation of demand response programs and its effect on the power system, and the development of business models for Smart Grids.

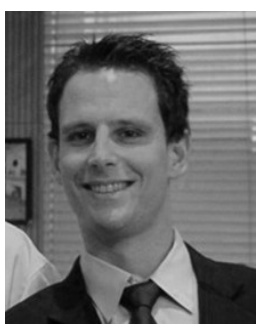

Pieter Vingerhoets received his M.Sc degree in physics in 2006 and his $\mathrm{PhD}$ degree in nuclear physics in 2010 at the KU Leuven, Belgium. He is postdoctoral researcher at the Electrical Energy research group ELECTA, at the department of electrical Engineering (ESAT) of the KU Leuven. He performs research and project coordination on monitoring and control in smart grids and ICT applications.

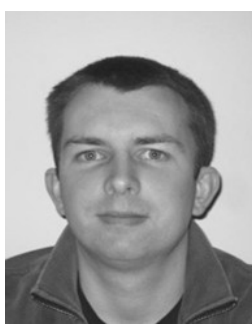

Peter Tant (S'05) received the M.Sc. degree from the Provinciale Industriële Hogeschool, Kortrijk, Belgium in 2003 and the M.Sc. and PhD degree from the KU Leuven, Belgium in 2005 and 2010 respectively, in electrical engineering. $\mathrm{He}$ is a researcher at the Electrical Energy research Group, ELECTA, of the department of electrical engineering of KU Leuven since 2005. His research interests are in the field of power electronics, measurement techniques and smart grid technologies.

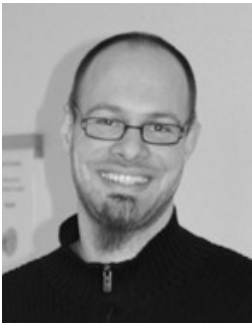

Koen Vanthournout received his Master's degree in Electrical Engineering (1999) from the Groep T Hogeschool of Leuven, Belgium, and his Master's degree in Artificial Intelligence (2000) from KU Leuven, Belgium. He obtained a $\mathrm{PhD}$ in Electrical Engineering from K.U. Leuven in 2006. Till 2009 he worked as a senior embedded software engineer for Icos Visions Systems/KLA-Tencor, after which he joined VITO, the Flemish Institute for Technological Research, where he is working on control systems for smart grids and active demand.

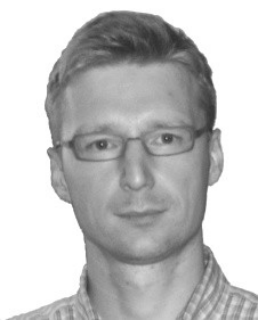

Wim Cardinaels graduated as Industrial Engineer in Electro-Mechanics in 1995 at KHLim, Diepenbeek, Belgium. He joined VITO in 2011 as project coordinator for the LINEAR project. From 1995 till 2011 he has been working in several functions in pharmaceutical related packaging companies in engineering and management. His experiences in process improvement, prototype development, system implementation and support in an operational environment are valuable for the LINEAR field test for which development, integration, implementation in the field and technical support, are crucial to make this demonstration project a success.

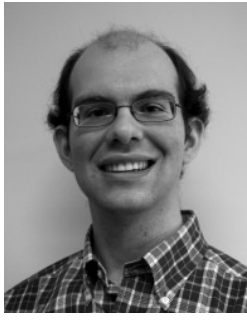

Tom De Rybel received the Industrial Engineer degree in electronics design from Hogeschool Gent, Gent, Belgium, in 2002 and the M.A.Sc and Ph.D. degrees in power systems from the University of British Columbia, Vancouver, BC, Canada in 2005 and 2010. He is currently at the Catholic University of Leuven as a post-doctoral fellow and industrial research manager. His research interests are transmission line modeling, numerical acoustics, power electronics, real-time simulation, high-voltage instrumentation, on-line asset condition monitoring, and component design for smart grid applications.

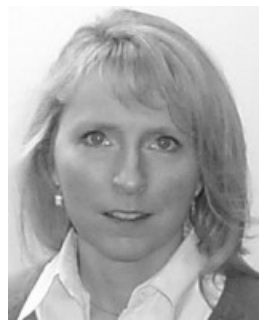

Eefje Peeters received her M.S. degree in electrical engineering in 1997 from the K.U.Leuven, Belgium. After a start in the electric design of power transformers at Pauwels Transformers in Mechelen, she started working at VITO in the unit Energy Technology in 1998. Here she worked on several national and European research projects in the field of thermal and electrical systems for the rational use of energy and renewable energy technologies such as wind and photovoltaic energy production. In 2008, she became the coordinator of the program "Smart systems for intelligent energy networks" within the unit Energy Technology. Since end 2009 she combined this with the coordination of the LINEAR project, a large scale pilot project for the implementation of active demand at the distribution grid in Flanders. As of April 2011 she became program manager of a team that works on thermal and electrical storage systems, sustainable grid connected vehicles and infrastructure and E-markets in a smart grid context.

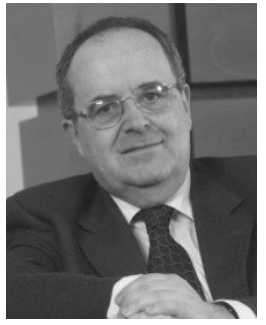

Ronnie Belmans (S'77-M'84-SM'89-F'05) received the M.S. degree in electrical engineering in 1979 and the Ph.D. degree in 1984, both from the KU Leuven, Belgium, the Special Doctorate in 1989 and the Habilitierung in 1993, both from the RWTH, Aachen, Germany. Currently, he is a full professor with the KU Leuven, teaching electric power and energy systems. His research interests include techno-economic aspects of power systems, power quality and distributed generation. He is also guest professor at Imperial College of Science, Medicine 